\title{
Assessing forgetfulness and polypharmacy and their impact on health-related quality of life among patients with hypertension and dyslipidemia in Greece during the COVID-19 pandemic
}

\author{
Kyriakos Souliotis $^{1,2} \cdot$ Theodoros V. Giannouchos $^{3}$ (I) $\cdot$ Chistina Golna ${ }^{2} \cdot$ Evangelos Liberopoulos $^{4}$
}

Accepted: 14 June 2021 / Published online: 22 June 2021

(c) The Author(s), under exclusive licence to Springer Nature Switzerland AG 2021

\begin{abstract}
Purpose We estimate the association between forgetfulness to take medications as prescribed and polypharmacy and healthrelated quality of life (HRQoL) among a cohort of patients with hypertension, dyslipidemia or both in Greece during the COVID-19 pandemic.

Methods A telephone survey of 1018 randomly selected adults was conducted in Greece in June 2020. Participants were included in the survey, if they (a) had a diagnosis of hypertension, dyslipidemia or both and (b) were on prescription treatment for these conditions. HRQoL was calculated using the short form (SF) -12 Patient Questionnaire. A multivariable generalized linear regression model (GLM) was used to estimate the association between forgetfulness and polypharmacy and HRQoL, controlling for sociodemographic and health-related covariates.

Results Overall, 351 respondents met the inclusion criteria, of whom 28 did not fully complete the questionnaire (response rate: $92 \%, n=323$ ). Of those, $37 \%$ were diagnosed with hypertension only, $28 \%$ with dyslipidemia only, and 35\% with both. Most reported good to average physical (64.1\%) and mental health (48.6\%). Overall, 25\% indicated that they sometimes forget to take their prescribed medications, and $12 \%$ took two or more pills multiple times daily. Total HRQoL score was $68.9 \%$ (s.d. $=18.0 \%$ ). About $10 \%$ of participants reported paying less attention to their healthcare condition during the pandemic. Estimates of multivariable analyses indicated a negative association between forgetfulness ( $-9 \%$, adjusted $\beta:-0.047,95 \%$ confidence interval -0.089 to $-0.005, p=0.029)$, taking two or more pills multiple times daily compared to one pill once a day $(-16 \%$, adjusted $\beta:-0.068,95 \%$ confidence interval -0.129 to $-0.008, p=0.028)$ and total HRQoL.

Conclusion Our results suggest that among adult patients with hypertension, dyslipidemia or both in Greece, those who forget to take their medications and those with more complex treatment regimens had lower HRQoL. Such patients merit special attention and require targeted approaches by healthcare providers to improve treatment compliance and health outcomes.
\end{abstract}

Keywords Polypharmacy $\cdot$ Forgetfulness $\cdot$ Quality of life $\cdot$ Hypertension $\cdot$ Dyslipidemia $\cdot$ Patient reported outcomes

\section{Introduction}

Theodoros V. Giannouchos

theo.giannouchos@utah.edu

1 Faculty of Social and Political Sciences, University of Peloponnese, Corinth, Greece

2 Health Policy Institute, Athens, Greece

3 Pharmacotherapy Outcomes Research Center, College of Pharmacy, University of Utah, 30 S 2000 E,

Salt Lake City, UT 84112, USA

4 Department of Medicine, Faculty of Medicine, University of Ioannina, Ioannina, Greece
Hypertension and dyslipidemia are among the most common chronic conditions worldwide and approximately one in every three adults has either or both medical conditions [1-3]. Over the past 30 years, the prevalence of hypertension has increased almost two-fold globally, while the number of deaths attributed to elevated cholesterol has increased by around 910,000 from 1990 to 2017, and similar trends have also been observed in Greece [4-6]. High cholesterol and blood pressure impair quality of life and cause more than 10 million deaths worldwide or $17 \%$ of total deaths and are equivalent to almost 87 million disability adjusted life years annually [7-10]. They also result in aggravated economic 
burden, due to treatment costs for managing these conditions, lost productivity and other economic costs [11].

There is regional heterogeneity in the prevalence of hypertension and dyslipidemia, attributed to population sociodemographic, clinical, and cultural characteristics [1-3]. For example, the traditional Mediterranean diet which is habitual among the Greek population has been associated with significant reductions in total mortality and incidence of cardiovascular events with improvements in overall health status $[12,13]$. Official guidelines and treatment practice, ranging from prescribed medications to lifestyle and dietary instructions, often consider and adjust for local population characteristics to meet diverse needs and to improve health outcomes [14].

Although the efficacy of existing treatments for hypertension and dyslipidemia has long been established in reducing mortality and morbidity and improving quality of life, more than half of patients treated for these conditions in Greece fail to achieve the targeted outcomes [15]. In addition, adherence to prescribed medications for these conditions, particularly when patients are treated with multiple medications, remains poor in everyday practice, thus impacting the realworld effectiveness of treatments [15-20].

Medication adherence refers to the degree of conformity to provider recommendations about day-to-day treatment with respect to timing, dosage, and frequency [21]. Inadequate medication adherence or non-adherence is mostly driven by forgetfulness, limits treatment outcomes and fails to improve or maintain a patient's health status, thus adversely affecting patients' health, productivity, health expenditures, and recourses' use [17, 20-27]. Multiple studies have indicated a positive association between increased medication adherence and quality of life and patient-centered outcomes [22-29]. In contrast, polypharmacy, which refers to the administration of multiple drugs at the same time, has been associated with lower quality of life [30-32]. However, there is some variation in outcomes depending on the disease-type, the population, and the setting analyzed [33].

Adherence is also related to patients' access to medications. Country-level economic and healthcare system capacity critically affect treatment patterns and access and adherence to medications across different settings. In Greece, prescription medications are reimbursed by the National Organization for Health Care Services Provision (EOPYY) and patients shoulder a co-payment ( $0 \%$ for life-threatening diseases, $10 \%$ for specific chronic diseases, $25 \%$ for all other) plus an out-of-pocket payment of the difference between health insurance contribution (defined according to available generic medications) and the retail price of pharmaceuticals [34]. Such co-payments are overall low, as Greece has among the lowest medication prices across the European Union, calculated as the average of the two lowest prices in the Euro zone [34]. This, combined with universal health insurance coverage and a high number of community pharmacies ( 88 per 100,000 individuals; highest across the OECD25 countries) help alleviate access and financial barriers and thus achieve and maintain high rates of medication adherence compared to other countries [35].

Beyond these considerations, the ongoing COVID-19 pandemic has profoundly disrupted healthcare provision and access to medications globally and adversely affected quality-of-life. Evidence in the United States and Latin America suggests that $8 \%$ to $16 \%$ of patients reported missing one or more doses of a prescription medicine during the pandemic [36, 37]. In contrast, studies conducted in other settings found no particular changes in medication adherence during the pandemic $[38,39]$.

In Greece, shelter in place orders were supplemented with the universal roll out of electronic prescriptions that substituted the need to visit a physician to renew a prescription for a chronic health condition. Additionally, the jobretention policy adopted by the Greek government during the pandemic, where monthly stimulus checks in the form of cash transfers were provided to workers on the condition of maintaining their employment and the prohibition of layoffs, mitigated large-scale unemployment, and maintained health insurance coverage [40]. To our knowledge, no study has provided evidence on the rates of forgetfulness and polypharmacy and their impact on health-related quality of life (HRQoL) among patients with hypertension and/or dyslipidemia in the era of COVID-19 pandemic in Greece.

This study explores forgetfulness to take medications as prescribed and polypharmacy and estimates their association with HRQoL among adult patients with hypertension and/ or dyslipidemia in Greece during the COVID-19 pandemic era. The results of this study expand and update the current evidence on the impact of forgetfulness to take medications and polypharmacy on HRQoL in an era where healthcare has received significant attention from the public. Providing such evidence might be helpful and guide healthcare providers and policymakers to tailor interventions towards enhancing adherence with important societal, economics, and health-related implications.

\section{Methods}

\section{Data and study sample}

We conducted a cross-sectional telephone survey with 1,018 randomly selected individuals in June 2020 in Greece. We included patients who (a) were diagnosed with hypertension, dyslipidemia, or both, (b) received prescribed medication(s) for these conditions, (c) were 18 years of age or older and (d) were fluent in the Greek language. The survey was 
designed by the researchers of the study and distributed by a commercial company working in the field of demographic surveys. The process was supported by computer-assisted telephone interviewing (CATI) specialized software. A multistage selection process was used to randomly select participants proportionately among the 13 administrative regions in Greece. De-identified data were collected for all participants after obtaining informed consent for participation in the study.

\section{Outcome measure}

The outcome measure of interest was patient HRQoL. To calculate HRQoL, we used the short form (SF) -12 patient questionnaire in Greek language which is a psychometric, multidimensional, generic measure of HRQoL that has been empirically established across multiple chronic conditions [41-43]. The SF-12 is a reduced form of the SF-36, a standardized questionnaire to assess patient health, which has proven equally reliable and thus more convenient to use and also validated in Greek language [42, 43]. The SF-12 contains 12 questions across 8 dimensions of health and can be used to produce total HRQoL scores, physical component HRQoL scores, and mental health component HRQoL scores. We adjusted the SF-12 to calculate all three HRQoL scores using percentage points, ranging from 0 (lowest) to $100 \%$ (highest).

\section{Main independent variable}

The main determinants of HRQoL were self-reported adherence to medications and polypharmacy. There are multiple scales that are currently used to measure medication adherence [44]. Among those, the most common question identifies patients' forgetfulness to take their medication and is considered the major cause of non-adherence. As such, we chose to use only this question, particularly due to the heterogeneity of existing questionnaires. We asked patients the following question as dichotomous "Do you sometimes forget to take your prescribed medication(s)?". In the absence of a unanimous definition of polypharmacy and since we focused on two chronic conditions, we asked patients to report how many different pills they were currently taking daily for each condition to measure disease and treatment complexity (polypharmacy). The measure was categorical and included three mutually exclusive categories, namely use of one pill once a day, one pill multiple times a day or more than one pill multiple times daily.

\section{Covariates}

We obtained sociodemographic characteristics, and health related information, which were used as controls in our analysis. Sociodemographic characteristics included participants' age, gender, income, area of residence, and education. Health related information included self-reported physical and mental health status, whether the respondent had at least one additional chronic condition, smoking status, regular exercise, alcohol use and dietary habits, which was assessed using a dichotomous question on the consumption of more than five portions of fruits and vegetables weekly. Finally, given the growing evidence on patients' foregoing or postponing healthcare services and necessary treatments during the COVID-19 pandemic, we further obtained information on participants behavior during the pandemic [36, 45]. In particular, we asked patients to report changes in their attention to their healthcare condition during the COVID-19 pandemic, phrased as "How did your attention to your healthcare condition change during the pandemic?" and measured as 'Decreased attention', 'No change', 'Increased attention'.

\section{Statistical analysis}

We initially performed a descriptive analysis to summarize characteristics and information of participants using percentages for categorical and dichotomous variables and means and standard deviations for numeric variables. We similarly analyzed and calculated the HRQoL scores. To estimate the association between forgetfulness and polypharmacy and HRQoL, we used a multivariable generalized linear regression model, controlling for all covariates including the type of diagnosis. Because the outcome variable (HRQoL) was potentially skewed, we initially performed a Shapiro-Wilk test to assess the normality of the distribution. The test indicated a non-normal distribution and we used Tukey's ladder of power for transformations to specify the appropriate adjustment. The test supported the use of squared values for the HRQoL variable, which was used in this form in the multivariable analysis. We included geographic level fixedeffects to control for time-invariant unobserved heterogeneity. We also controlled for the type of chronic condition and standard errors were robust to heteroskedasticity. We further tested for multicollinearity using the variance inflation factor. Finally, we conducted supplemental analyses as robustness checks, with physical and mental health HRQoL scores as outcomes variables separately. All statistical analyses were conducted in Stata (version 16.1; StataCorp, College Station, TX).

\section{Results}

\section{Descriptive characteristics of study population}

A total of 351 respondents met the inclusion criteria. Of those 28 did not fully complete the questionnaire. This 
resulted in 323 participants as the final analytic sample (response rate: $92 \%$ ). Table 1 presents sample characteristics (Table 1). About 37\% were diagnosed and currently received prescribed medications for hypertension, $28 \%$ for dyslipidemia and about $35 \%$ for both conditions. The majority were males $(55.1 \%), 65$ years of age or older (40.9\%), with average or higher income $(65.3 \%)$ and resided in urban areas (70.0\%). Most had never smoked or were former smokers, while $7.9 \%$ reported daily consumption of alcohol. Consumption of more than 5 portions weekly of fruits and vegetables was reported by $57.0 \%$, whereas physical activity (exercise) was balanced.

In terms of self-reported physical and mental health, the majority described their health as good or average across both dimensions (physical: 64.1\%; mental: 48.6\%). However, $11.5 \%$ and $9.9 \%$ considered their physical and mental health as bad or very bad, respectively. More than onethird of participants (39.9\%) reported having an additional chronic condition.

Most participants (73.7\%) indicated that their treatment included one pill once a day, and $12.4 \%$ reported using two or more pills multiple times daily (Table 2). About one quarter $(25.1 \%)$ revealed that they sometimes forget to take their prescribed medications. In terms of respondents' changes in attention to their healthcare condition during the pandemic, the majority reported no change in their behavior $(67.8 \%$ ), while $22.6 \%$ reported increased and $9.6 \%$ decreased attention.

\section{Health-related quality of life findings based on the SF-12 patient questionnaire}

Table 3 presents the self-reported HRQoL assessment (Table 3). Total score was $68.9 \%$ (standard deviation $=18.0 \%$ ), while results were similar for the physical component $(69.3 \%$, s.d. $=22.3 \%)$ and mental component $(68.7 \%$, s.d. $=19.0 \%)$ subscores. Limitations in moderate activities and climbing stairs were reported by $27.2 \%$ and $59.1 \%$ of patients respectively. Almost one in every four participants revealed that they accomplished less (25.7\%) and that they were limited in work or other activities $(25.1 \%)$ because of their physical health, while $8.7 \%$ never or rarely had a lot of energy during the past four weeks. About $40 \%$ indicated pain had a small to an extreme impact on their normal work. In terms of emotional health, $26.6 \%$ accomplished less and $21.0 \%$ were less careful during work or other activities due to emotional problems, $12.7 \%$ rarely or never felt calm and peaceful, and 5.3\% very often or always felt downhearted and blue during the past 4 weeks. About $8 \%$ of patients reported facing issues with social activities very often or constantly due to their physical or mental health.
Table 1 Descriptive characteristics of participants $(n=323)$

\begin{tabular}{|c|c|}
\hline & $\begin{array}{l}\text { Participants } n=323 \\
\text { Percentage }(\%)\end{array}$ \\
\hline Hypertension & 37.1 \\
\hline Dyslipidemia & 27.9 \\
\hline Both & 35.0 \\
\hline \multicolumn{2}{|l|}{ Gender } \\
\hline Male & 55.1 \\
\hline Female & 44.9 \\
\hline \multicolumn{2}{|l|}{ Age groups } \\
\hline 25 to 54 & 29.7 \\
\hline 55 to 64 & 29.4 \\
\hline$\geq 65$ & 40.9 \\
\hline \multicolumn{2}{|l|}{ Area of residence } \\
\hline Urban & 70.0 \\
\hline Rural & 30.0 \\
\hline \multicolumn{2}{|l|}{ Education } \\
\hline Lower than high school & 19.2 \\
\hline High school & 33.1 \\
\hline University & 36.5 \\
\hline Masters/doctoral & 11.2 \\
\hline \multicolumn{2}{|l|}{ Income } \\
\hline Lower than average & 34.7 \\
\hline Average or higher & 65.3 \\
\hline \multicolumn{2}{|c|}{ Additional comorbidity (at least one) } \\
\hline No & 60.1 \\
\hline Yes & 39.9 \\
\hline \multicolumn{2}{|l|}{ Smoking status } \\
\hline Never smoked & 32.8 \\
\hline Former smoker & 36.2 \\
\hline Current smoker & 31.0 \\
\hline \multicolumn{2}{|c|}{ Exercise (30 $\mathrm{min} /$ day or $3 \mathrm{~h} /$ week) } \\
\hline No & 28.8 \\
\hline Yes, but less than $3 \mathrm{~h} /$ week & 33.4 \\
\hline Yes, $3 \mathrm{~h} /$ week or more & 37.8 \\
\hline \multicolumn{2}{|l|}{ Alcohol consumption } \\
\hline No & 45.6 \\
\hline Occasionally & 46.5 \\
\hline Daily & 7.9 \\
\hline \multicolumn{2}{|c|}{ Fruit and vegetables consumption (more than 5 portions/week) } \\
\hline No & 43.0 \\
\hline Yes & 57.0 \\
\hline \multicolumn{2}{|l|}{ Self-reported physical health } \\
\hline Bad/very bad & 11.5 \\
\hline Good/average & 64.1 \\
\hline Very good/excellent & 24.4 \\
\hline \multicolumn{2}{|l|}{ Self-reported mental health } \\
\hline Bad/very bad & 9.9 \\
\hline Good/average & 48.6 \\
\hline Very good/excellent & 41.5 \\
\hline
\end{tabular}


Table 2 Forgetfulness, polypharmacy, and changes in attention to the healthcare condition during the pandemic

\begin{tabular}{lc}
\hline & $\begin{array}{l}\text { Participants } n=323 \\
\text { Percentage (\%) }\end{array}$ \\
\hline Do you sometimes forget to take your prescribed medication(s)? & \\
No & 74.9 \\
Yes & 25.1 \\
Number of pills/times/day for each condition & \\
One pill once a day & 73.7 \\
One pill multiple times daily & 13.9 \\
More than one pill multiple times daily & 12.4 \\
How did your attention to your healthcare condition change during the pandemic? & \\
Decreased & 9.6 \\
Did not change & 67.8 \\
Increased & 22.6 \\
\hline
\end{tabular}

\section{Multivariable generalized linear regression findings}

Estimates of the multivariable generalized model indicated a statistically significant and negative association between forgetfulness to take prescribed medications and total HRQoL, with patients who forgot to take their medication having 6.1 percentage points lower HRQoL (coefficient $=-0.047$, $95 \%$ confidence interval $-\mathrm{CI}-0.089$ to $-0.005, p=0.029$ ) (Table 4, Fig. 1). Decreased total HRQoL was also observed in patients who took more than one medication multiple times daily compared to those who took one pill once a day, with an absolute difference of 11.5 percentage points (coefficient $=-0.068,95 \% \mathrm{CI}-0.129$ to $-0.008, p=0.028)$. Similar results were obtained in the supplemental analyses for the physical and mental health components separately. Behavioral changes in participants attention to their healthcare condition during the pandemic were not statistically significant.

Additional covariates that were positively associated with HRQoL included better self-reported physical and mental health status compared to those who perceived their physical and mental health as bad or very bad ( $p<0.001$ for all), and regular exercise for more than $3 \mathrm{~h} /$ week compared to those who did not exercise (coefficient $=0.059,95 \%$ CI $0.013-0.104, p=0.011)$. Finally, daily alcohol consumption, and female gender were negatively associated with HRQoL.

\section{Discussion}

The results of our study indicate that forgetfulness to adhere to prescribed medications and taking more than one pill multiple times daily were negatively associated with HRQoL ( $-9 \%$ and $-16 \%$ lower respectively) among a nationally representative cohort of patients who were diagnosed and received prescription medication treatment for hypertension, dyslipidemia, or both in Greece. These findings are supported by previous studies and suggest that, since these conditions can be effectively controlled and treated through medication therapy, increased compliance and less complex treatment regimens result in improved clinical outcomes, and, thus, reduce or eliminate symptoms which in turn improve functioning and HRQoL [22-32, 46-48].

In our study, one in every four patients indicated that they forget to take their medication as prescribed. This finding is encouraging since it is lower than estimates found in other studies, where $36 \%$ to $70 \%$ of patients reported forgetting to take their medications, while Greek patients were found to be among the least compliant patients across nine European countries $[19,49-51]$. We note that this result might be related to the large share of patients who reported paying more attention to their healthcare condition during the COVID-19 pandemic, in the context of affordable medications in Greece, providers' ability to issue prescriptions electronically and updated legislation to subsidize and protect employment and social health insurance during the pandemic. This highlights the positive effects of such policies on population health as well as patients' willingness to improve their quality of life.

However, about $10 \%$ of participants reported paying less attention to their health condition during the pandemic. Although we did not observe any significant association between patients' changes in attention to their healthcare condition during the pandemic and HRQoL, HRQoL was relatively lower for those who reported decreasing attention to their condition. There is currently growing literature on patients' foregoing or postponing necessary healthcare services during the pandemic [36, 45]. In Greece, such an impact has been mitigated by effective measures implemented from the breakout of COVID-19, which have sustained affordability, enabled safe access to care and upheld insurance coverage.

The self-reported HRQoL was around 16\% lower among patients on treatment with multiple pills daily 
Table 3 Health-related quality of life results using the 12-item Short Form Survey (SF-12) patient questionnaire results using the 12-item Short Form Survey (SF-12) patient questionnaire

Participants $n=323$

Percentage $(\%)$

Total SF-12 score

$68.9(18.0)$

Physical component SF-12 score

$69.3(22.3)$

Mental component SF-12 score

$68.7(19.0)$

In general, would you say your health is:

Excellent

Very good

Good

Fair

Poor

Does your health now limit you in moderate activities (i.e. moving a table, pushing a vacuum cleaner)?

Not at all

Yes, a bit

Yes, a lot

Does your health now limit you in climbing several flights of stairs?

Not at all

Yes, a bit

Yes, a lot

During the past 4 weeks, have you as a result of your physical accomplished less than you would like?

No

Yes

During the past 4 weeks, were you as a result of your physical health limited in the kind of work or other activities?

No

Yes

During the past 4 weeks, how much did pain interfere with your normal work?

Not at all

A little bit

Moderately

Quite a bit

Extremely

During the past 4 weeks, did you have a lot of energy?

Never

Rarely

Sometimes

Often

Very often

Always

During the past 4 weeks, have you as a result of your emotional problems accomplished less than you would like?

No

Yes

During the past 4 weeks, have you as a result of your emotional problems not done work or other activities as carefully as usual?

No

Yes

During the past 4 weeks, have you felt calm and peaceful?

Never

Rarely 
Table 3 (continued)

\begin{tabular}{ll}
\hline & $\begin{array}{c}\text { Participants } n=323 \\
\text { Percentage (\%) }\end{array}$ \\
\hline Always & 12.1 \\
During the past 4 weeks, did you feel downhearted and blue? & 37.8 \\
Never & 19.2 \\
Rarely & 25.4 \\
Sometimes & 12.4 \\
Often & 3.7 \\
Very often & 1.6 \\
Always & \\
During the past 4 weeks, how much of the time has your physical health or emotional problems interfered with your social & \\
activities (visiting friends, relatives etc.)? & \\
Never & \\
Rarely & \\
Sometimes & \\
Often & \\
Very often & \\
Always & \\
\hline
\end{tabular}

compared to those with one pill once a day, consistent with previous work [30-32]. However, forgetfulness, decreased attention, and complex treatment regimens and polypharmacy are modifiable, through targeted interventions. Multiple studies have explored such interventions and their outcomes on quality-of-life [22, 52, 53]. Most of the initiatives that have positively impacted treatment compliance focus on establishing a good patient-provider relationship, patients' education and counselling tips, shared-decision making and patient input on treatment choices, and adherence feedback [18, 20, 22, 52, 54-56]. Except for patient-provider communication, utilizing novel technological tools such as mobile-phone-based automated medication reminder systems have also proven effective in improving medication adherence [57, 58].

Our results also indicate the importance of lifestyle interventions to improve patients' HRQoL. Regular exercise and decreased alcohol consumption were significantly associated with higher HRQoL, similar to previous work [59]. Other characteristics and factors associated with impaired HRQoL in our study, such as female gender, and worse self-perceived mental and physical health, are in line with findings from several previous studies [60-62]. The association between gender differences and HRQoL could be attributed to the fact that men might be better able to tolerate chronic diseases [60]. Finally, worse physical and mental health status and alcohol use negatively influence daily activities which is reflected in the HRQoL outcomes, as expected.

\section{Limitations}

Our findings are based on self-reported survey data, and may thus be prone to report, recall, and social desirability biases. Second, our estimates regarding the prevalence of both conditions might underestimate the actual prevalence of hypertension and/or dyslipidemia in Greece. However, undiagnosed or asymptomatic patients do not receive treatment for these conditions, which was an inclusion criterion for our study, and, thus, do not affect our results. Third, the question regarding changes in attention to the healthcare condition during the pandemic did not allow us to capture potential changes in the ability to adhere or to access needed medications, which could be additional confounders. Fourth, we highlight that due to the cross-sectional study design, we cannot rule out the possibility of reverse causality between HRQoL and adherence. Despite, multiple studies, which we reference throughout, have examined variations in HRQoL as being driven by changes in adherence. Finally, we note that forgetfulness as a sole measure of adherence is indicative only of unintentional non-adherence and thus might not capture the full spectrum of other factors, such as inability to pay and limited access to providers (intentional non-adherence). Despite, forgetfulness is the most influential and commonly used question in existing and validated medication adherence scales, and thus we believe that it is a robust estimator of both overall adherence and HRQoL [44]. 
Table 4 Multivariable generalized linear model estimations on the associations between patient characteristics and health-related quality of life $(n=323)$

Do you sometimes forget to take your prescribed medication(s)?

\section{No}

Yes

Number of pills/times/day for each condition

One pill once a day

One pill multiple times daily

More than one pill multiple times daily

How did your attention to your healthcare condition change during the pandemic?

Decreased

No change

Increased

Physical health

Bad/very bad

Good/average

Very good/excellent

Mental health

Bad/very bad

Good/average

Very good/excellent

Additional comorbidity (at least one)

\section{No}

Yes

Exercise (30 min/day or $3 \mathrm{~h} /$ week)

No

Yes, but less than $3 \mathrm{~h} /$ week

Yes, $3 \mathrm{~h}$ /week or more

Alcohol consumption

No

Occasionally

Daily

Gender

Male

Female

Age groups

25 to 54

55 to 64

$65+$

Area of residence

Urban

Rural

Education

University

Masters/doctoral

High school

Less than high school

Income

Higher than average

Lower than average
Ref.

$-0.047 \quad-0.089$ to -0.005

0.029

Ref.

0.001

$-0.068$

$$
-0.045-0.047
$$

-0.129 to -0.008

0.028

Ref.

0.041

0.017

$-0.014-0.095$

0.143

$-0.050-0.083$

0.624

Ref.

0.131

$0.070-0.192$

$<0.001$

0.201

$0.126-0.276$

$<0.001$

Ref.

$\begin{array}{lll}0.181 & 0.129-0.232 & <0.001 \\ 0.301 & 0.242-0.359 & <0.001\end{array}$

Ref.

Ref.

$-0.029$

$-0.068-0.010$

0.146

Ref.

$-0.006$

$-0.053-0.041$

0.801

0.059

$0.013-0.104$

0.011

Ref.

0.008

$-0.069$

$-0.031-0.048$

0.682

Ref.

$-0.053$

-0.098 to -0.008

0.022

Ref.

0.018

$-0.021$

$-0.030-0.065$

0.469

$-0.137-0.025$

0.374

Ref.

$-0.030$

$-0.072-0.004$

0.172

Ref.

0.030

- 0.026-0.086

0.299

0.025

$-0.032-0.083$

0.390

0.040

$-0.042-0.122$

0.334

Ref.

0.024 
Table 4 (continued)

\section{Coefficient}

$95 \% \mathrm{CI}$

$p$ value

Smoking status

Never smoked

Ref.

Former smoker

$-0.001$

$-0.048-0.046$

0.961

Current smoker

$-0.035-0.057$

0.641

Fruit and vegetables consumption (more than 5 portions/week)

No

Ref.

Yes

0.014

$-0.024-0.052$

The analysis controls for geographic-level fixed effects and type of condition (hypertension, dyslipidemia, both); standard errors were robust to heteroskedasticity

CI confidence intervals; Ref. reference

Fig. 1 Association between forgetfulness and polypharmacy and health-related quality of life results using the 12 -item Short Form Survey (SF-12) patient questionnaire based on the multivariable analysis. Notes: The figure is based on the estimates (predictive values) of the multivariate generalized linear model

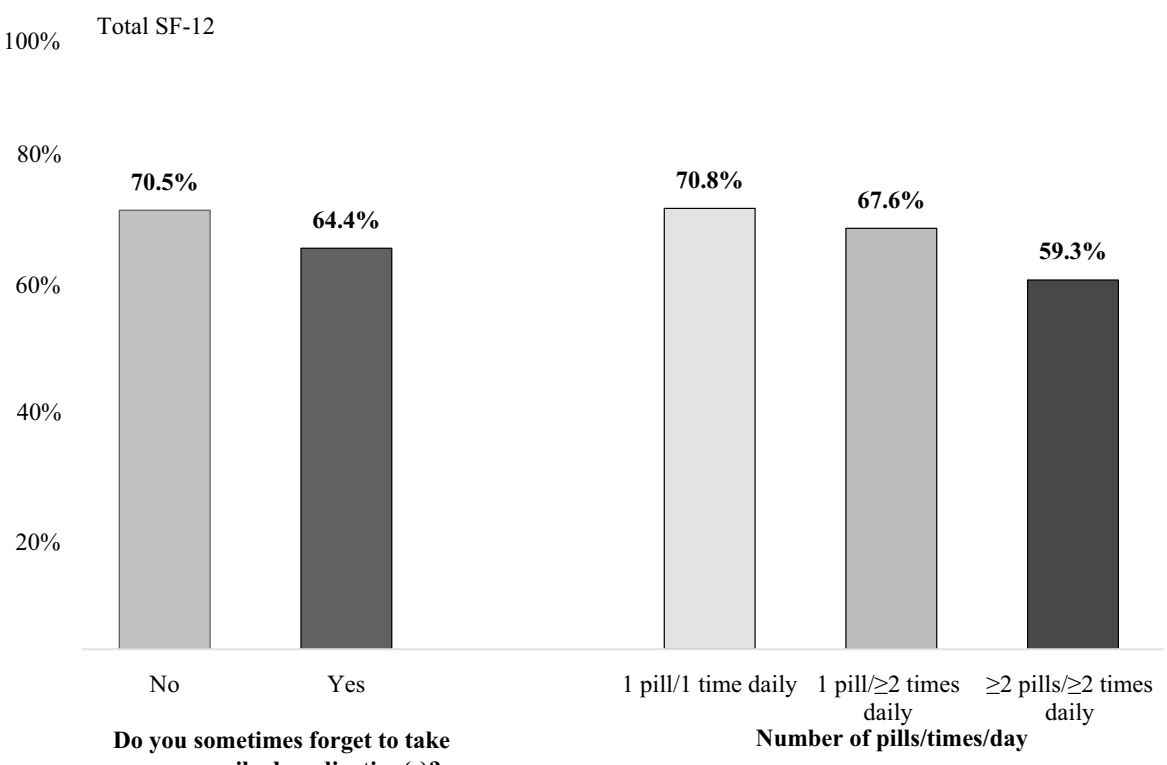

Notes: The figure is based on the estimates (predictive values) of the multivariate generalized linear model

\section{Conclusion}

Forgetfulness to take medications as prescribed and polypharmacy are independent factors associated with HRQoL among patients with hypertension, dyslipidemia or both in Greece. Addressing those is challenging due to the inherent complexity of individual treatment and lifestyle preferences and patient-provider relationships. Effective strategies to improve patients' HRQoL should involve patients in the decision-making processes and promote routine adherence screening and consultation, tailored at individual patient needs.

Funding This study was funded by Servier Hellas. The study results were not contingent on the sponsor's approval or censorship of the manuscript.
Data availability Data are available upon request.

\section{Declarations}

Conflict of interest The authors declares that they have no conflict of interest.

Ethical approval All procedures were in accordance with the ethical standards of the institutional and/or national research committee and with the 1964 Helsinki Declaration and its later amendments or comparable ethical standards. The study was approved by an independent research ethics committee of the Health Policy Institute, Athens, Greece.

\section{References}

1. Mills, K. T., Stefanescu, A., \& He, J. (2020). The global epidemiology of hypertension. Nature Reviews Nephrology, 5, 1-5. 
2. Venkitachalam, L., Wang, K., Porath, A., Corbalan, R., Hirsch, A. T., Cohen, D. J., Smith, S. C., Jr., Ohman, E. M., Steg, P. G., Bhatt, D. L., Magnuson, E. A., \& REACH Registry Investigators. (2012). Global variation in the prevalence of elevated cholesterol in outpatients with established vascular disease or 3 cardiovascular risk factors according to national indices of economic development and health system performance. Circulation, 125(15), $1858-1869$.

3. https://www.who.int/news-room/fact-sheets/detail/hypertension. Accessed on 18 Aug 2020

4. Zhou, B., Bentham, J., Di Cesare, M., Bixby, H., Danaei, G., Cowan, M. J., Paciorek, C. J., Singh, G., Hajifathalian, K., Bennett, J. E., \& Taddei, C. (2017). Worldwide trends in blood pressure from 1975 to 2015: A pooled analysis of 1479 populationbased measurement studies with 19.1 million participants. The Lancet, 389(10064), 37-55.

5. Taddei, C., Zhou, B., Bixby, H., \& NCD Risk Factor Collaboration (NCD-RisC). (2020). Repositioning of the global epicentre of non-optimal cholesterol. Nature, 4(582), 73-77.

6. Panagiotakos, D. B., Georgousopoulou, E. N., Pitsavos, C., Chrysohoou, C., Metaxa, V., Georgiopoulos, G. A., Kalogeropoulou, K., Tousoulis, D., Stefanadis, C., \& ATTICA Study group. (2015). Ten-year (2002-2012) cardiovascular disease incidence and allcause mortality, in urban Greek population: The ATTICA study. International Journal of Cardiology, 180, 178-84.

7. Jia, H., Zack, M. M., \& Thompson, W. W. (2013). The effects of diabetes, hypertension, asthma, heart disease, and stroke on quality-adjusted life expectancy. Value in Health, 16(1), 140-147.

8. Trevisol, D. J., Moreira, L. B., Kerkhoff, A., Fuchs, S. C., \& Fuchs, F. D. (2011). Health-related quality of life and hypertension: A systematic review and meta-analysis of observational studies. Journal of Hypertension, 29(2), 179-188.

9. https://www.who.int/gho/ncd/risk_factors/blood_pressure_preva lence_text/en/\#: :text=Worldwide $\% 2 \mathrm{C} \% 20 \mathrm{raised} \% 20 \mathrm{blood} \%$ 20pressure\%20is,or\% 203.7\%25\%20of\%20total\%20DALYS. Accessed on 19 Aug 2020

10. https://www.who.int/gho/ncd/risk_factors/cholesterol_text/en/. Accessed on 19 Aug 2020

11. Sullivan, P. W., Ghushchyan, V., Wyatt, H. R., Wu, E. Q., \& Hill, J. O. (2007). Productivity costs associated with cardiometabolic risk factor clusters in the United States. Value in Health, 10(6), 443-450.

12. Sofi, F., Cesari, F., Abbate, R., Gensini, G. F., \& Casini, A. (2008). Adherence to Mediterranean diet and health status: Meta-analysis. BMJ, 337, a1344.

13. Estruch, R., Ros, E., Salas-Salvadó, J., Covas, M. I., Corella, D., Arós, F., Gómez-Gracia, E., Ruiz-Gutiérrez, V., Fiol, M., Lapetra, J., \& Lamuela-Raventos, R. M. (2013). Primary prevention of cardiovascular disease with a Mediterranean diet. New England Journal of Medicine, 368(14), 1279-1290.

14. Alexopoulos, D., Anastasiou-Nana, M., Elisaf, M. S., Liberopoulos, E., Rallidis, L. S., Davos, C. H., Moulis, A., Nikas, N., Zacharis, E., Vardas, P., \& CHALLENGE Investigators. (2016). A contemporary cross-sectional study on dyslipidemia management, cardiovascular risk status, and patients' quality of life in Greece: The CHALLENGE study. International Journal of Cardiology, 217, 183-189.

15. Liberopoulos, E., Vlasserou, F., Mitrogianni, Z., Papageorgantas, I., \& Elisaf, M. (2012). Prevalence and risk distribution of residual dyslipidemia in statin-treated patients in Greece. Angiology, 63(3), 184-193.

16. Liberopoulos, E. N., Florentin, M., Mikhailidis, D. P., \& Elisaf, M. S. (2008). Compliance with lipid-lowering therapy and its impact on cardiovascular morbidity and mortality. Expert Opinion on Drug Safety, 7(6), 717-725.
17. Lalonde, L., Blais, L., Bérard, A., \& Perreault, S. (2010). Relationship between adherence level to statins, clinical issues and health-care costs in real-life clinical setting. Value in Health, 13(1), 87-94.

18. Schoenthaler, A., Rosenthal, D. M., Butler, M., \& Jacobowitz, L. (2018). Medication adherence improvement similar for shared decision-making preference or longer patient-provider relationship. Journal of the American Board of Family Medicine, 31(5), 752-760.

19. Morrison, V. L., Holmes, E. A., Parveen, S., Plumpton, C. O., Clyne, W., De Geest, S., Dobbels, F., Vrijens, B., Kardas, P., \& Hughes, D. A. (2015). Predictors of self-reported adherence to antihypertensive medicines: A multinational, cross-sectional survey. Value in Health, 18(2), 206-216.

20. Tsiantou, V., Pantzou, P., Pavi, E., Koulierakis, G., \& Kyriopoulos, J. (2010). Factors affecting adherence to antihypertensive medication in Greece: Results from a qualitative study. Patient Preference and Adherence, 4, 335.

21. Ho, P. M., Magid, D. J., Shetterly, S. M., Olson, K. L., Maddox, T. M., Peterson, P. N., Masoudi, F. A., \& Rumsfeld, J. S. (2008). Medication nonadherence is associated with a broad range of adverse outcomes in patients with coronary artery disease. American Heart Journal, 155(4), 772-779.

22. Conn, V. S., Ruppar, T. M., \& Cooper, P. S. (2016). Patient-centered outcomes of medication adherence interventions: Systematic review and meta-analysis. Value in Health, 19(2), 277-285.

23. Walsh, C. A., Bennett, K. E., Wallace, E., \& Cahir, C. (2020). Identifying adherence patterns across multiple medications and their association with health outcomes in older community-dwelling adults with multimorbidity. Value in Health. https://doi.org/ 10.1016/j.jval.2020.03.016

24. Bonaventura, M., Copher, R., Basurto, E., Faria, C., \& Lorenzo, R. (2014). The association between non-adherence and quality of life among women with metastatic breast cancer. Value in Health, 17(3), A92.

25. Patrick, A. R., Shrank, W. H., Glynn, R. J., Solomon, D. H., Dormuth, C. R., Avorn, J., Cadarette, S. M., Mogun, H., \& Brookhart, M. A. (2011). The association between statin use and outcomes potentially attributable to an unhealthy lifestyle in older adults. Value in Health, 14(4), 513-20.

26. Jneid, S., Jabbour, H., Hajj, A., Sarkis, A., Licha, H., Hallit, S., \& Khabbaz, L. R. (2018). Quality of life and its association with treatment satisfaction, adherence to medication, and trust in physician among patients with hypertension: A cross-sectional designed study. Journal of Cardiovascular Pharmacology and Therapeutics, 23(6), 532-542.

27. Sokol, M. C., McGuigan, K. A., Verbrugge, R. R., \& Epstein, R. S. (2005). Impact of medication adherence on hospitalization risk and healthcare cost. Medical Care, 1, 521-530.

28. Silavanich, V., Nathisuwan, S., Phrommintikul, A., \& Permsuwan, U. (2019). Relationship of medication adherence and quality of life among heart failure patients. Heart and Lung, 48(2), 105-110.

29. Zioga, E., Kazakos, K., Dimopoulos, E., Koutras, C., Marmara, K., Marmara, E. E., Marmaras, A., \& Lavdaniti, M. (2016). Adherence and quality of life in patients with type II diabetes mellitus in northern Greece. Materia Socio-Medica, 28(4), 258.

30. Schenker, Y., Park, S. Y., Jeong, K., Pruskowski, J., Kavalieratos, D., Resick, J., Abernethy, A., \& Kutner, J. S. (2019). Associations between polypharmacy, symptom burden, and quality of life in patients with advanced, life-limiting illness. Journal of General Internal Medicine, 34(4), 559-66.

31. Vyas, A., Kang, F., \& Barbour, M. (2020). Association between polypharmacy and health-related quality of life among US adults with cardiometabolic risk factors. Quality of Life Research, 29(4), 977-986. 
32. Vyas, A., Alghaith, G., \& Hufstader-Gabriel, M. (2020). Psychotropic polypharmacy and its association with health-related quality of life among cancer survivors in the USA: A population-level analysis. Quality of Life Research, 29(8), 2029-2037.

33. Martínez, Y. V., Prado-Aguilar, C. A., Rascón-Pacheco, R. A., \& Valdivia-Martínez, J. J. (2008). Quality of life associated with treatment adherence in patients with type 2 diabetes: A crosssectional study. BMC Health Services Research, 8(1), 164.

34. Yfantopoulos, J. N., \& Chantzaras, A. (2018). Drug policy in Greece. Value Health Regional Issues, 1(16), 66-73.

35. Organisation for Economic Co-operation and Development (OECD). (2019). Health at a glance 2019: Pharmacists and pharmacies. OECD Publishing, Paris. https://doi.org/10.1787/ 888934018070

36. Anderson, K. E., McGinty, E. E., Presskreischer, R., \& Barry, C. L. (2021). Reports of forgone medical care among US adults during the initial phase of the COVID-19 pandemic. JAMA Network Open, 4(1), e2034882.

37. Pineda-Sic, R. A., Galarza-Delgado, D. A., Serna-Peña, G., Castillo-Torres, S. A., Flores-Alvarado, D. E., Esquivel-Valerio, J. A., \& Hernández-Galarza, I. D. (2021). Treatment adherence behaviours in rheumatic diseases during COVID-19 pandemic: a Latin American experience. Annals of the Rheumatic Diseases, 80(6), e85.

38. Fragoulis, G. E., Evangelatos, G., Arida, A., Bournia, V. K., Fragiadaki, K., Karamanakos, A., Kravvariti, E., Laskari, K., Panopoulos, S., Pappa, M., \& Tektonidou, M. G. (2021). Treatment adherence of patients with systemic rheumatic diseases in COVID-19 pandemic. Annals of the Rheumatic Diseases, 80(4), e60.

39. Kaye, L., Theye, B., Smeenk, I., Gondalia, R., Barrett, M. A., \& Stempel, D. A. (2020). Changes in medication adherence among patients with asthma and COPD during the COVID-19 pandemic. The Journal of Allergy and Clinical Immunology: In Practice, 8(7), 2384-2385.

40. Betcherman, G., Giannakopoulos, N., Laliotis, I., Pantelaiou, I., Testaverde, M., \& Tzimas, G. (2020). Reacting quickly and protecting jobs: The short-term impacts of the COVID-19 lockdown on the Greek labor market. Washington: World Bank.

41. Gandek, B., Ware, J. E., Aaronson, N. K., Apolone, G., Bjorner, J. B., Brazier, J. E., Bullinger, M., Kaasa, S., Leplege, A., Prieto, L., \& Sullivan, M. (1998). Cross-validation of item selection and scoring for the SF-12 health survey in nine countries: Results from the IQOLA project. Journal of Clinical Epidemiology, 51, 1171-8.

42. Brazier, J. E., \& Roberts, J. (2004). The estimation of a preference-based measure of health from the SF-12. Medical Care, $1,851-859$.

43. Kontodimopoulos, N., Pappa, E., Niakas, D., \& Tountas, Y. (2007). Validity of SF-12 summary scores in a Greek general population. Health and Quality of Life Outcomes, 5(1), 1-9.

44. Nguyen, T. M., Caze, A. L., \& Cottrell, N. (2014). What are validated self-report adherence scales really measuring?: A systematic review. British Journal of Clinical Pharmacology, 77(3), 427-445.

45. Giannouchos, T. V., Biskupiak, J., Moss, M. J., Brixner, D., Andreyeva, E., \& Ukert, B. (2021). Trends in outpatient emergency department visits during the COVID-19 pandemic at a large, urban, academic hospital system. American Journal of Emergency Medicine, 40, 20-6.

46. Chew, B. H. (2015). Medication adherence on quality of life among adults with type 2 diabetes mellitus: An exploratory analysis on the EDDMQoL study. Quality of Life Research, 24(11), 2723-2731.

47. Khayyat, S. M., Mohamed, M. M., Khayyat, S. M., Alhazmi, R. S., Korani, M. F., Allugmani, E. B., Saleh, S. F., Mansouri,
D. A., Lamfon, Q. A., Beshiri, O. M., \& Hadi, M. A. (2019). Association between medication adherence and quality of life of patients with diabetes and hypertension attending primary care clinics: A cross-sectional survey. Quality of Life Research, 28(4), 1053-61.

48. Bulloch, A. G., Adair, C. E., \& Patten, S. B. (2006). Forgetfulness: A role in noncompliance with antidepressant treatment. Canadian Journal of Psychiatry, 51(11), 719-722.

49. Park, H. Y., Seo, S. A., Yoo, H., \& Lee, K. (2018). Medication adherence and beliefs about medication in elderly patients living alone with chronic diseases. Patient Preference and Adherence, 12,175 .

50. Weidenbacher, H. J., Beadles, C. A., Maciejewski, M. L., Reeve, B. B., \& Voils, C. I. (2015). Extent and reasons for nonadherence to antihypertensive, cholesterol, and diabetes medications: The association with depressive symptom burden in a sample of American veterans. Patient Preference and Adherence, 9, 327.

51. Karakurt, P., \& Kaşikçi, M. (2012). Factors affecting medication adherence in patients with hypertension. Journal of Vascular Nursing, 30(4), 118-126.

52. Nieuwlaat, R., Wilczynski, N., Navarro, T., Hobson, N., Jeffery, R., Keepanasseril, A., Agoritsas, T., Mistry, N., Iorio, A., Jack, S., Sivaramalingam, B., Iserman, E., Mustafa, R. A., Jedraszewski, D., Cotoi, C., \& Haynes, R. B. (2014). Interventions for enhancing medication adherence. Cochrane Database of Systematic Reviews. https://doi.org/10.1002/14651858.CD000011. pub4

53. Pages-Puigdemont, N., Mangues, M. A., Masip, M., Gabriele, G., Fernández-Maldonado, L., Blancafort, S., \& Tuneu, L. (2016). Patients' perspective of medication adherence in chronic conditions: A qualitative study. Advances in Therapy, 33(10), 1740-54.

54. Montori, V. M., Brito, J. P., \& Murad, M. H. (2013). The optimal practice of evidence-based medicine: Incorporating patient preferences in practice guidelines. JAMA, 310(23), 2503-2504.

55. Aschmann, H. E., Boyd, C. M., Robbins, C. W., Chan, W. V., Mularski, R. A., Bennett, W. L., Sheehan, O. C., Wilson, R. F., Bayliss, E. A., Leff, B., \& Armacost, K. (2020). Informing patient-centered care through stakeholder engagement and highly stratified quantitative benefit-harm assessments. Value in Health, 23(5), 616-624.

56. Witticke, D., Seidling, H. M., Klimm, H. D., \& Haefeli, W. E. (2012). Do we prescribe what patients prefer? Pilot study to assess patient preferences for medication regimen characteristics. Patient Preference and Adherence, 6, 679.

57. Choi, A., Lovett, A. W., Kang, J., Lee, K., \& Choi, L. (2015). Mobile applications to improve medication adherence: Existing apps, quality of life and future directions. Advances in Pharmacology and Pharmacy, 3(3), 64-74.

58. Patel, S., Jacobus-Kantor, L., Marshall, L., Ritchie, C., Kaplinski, M., Khurana, P. S., \& Katz, R. J. (2013). Mobilizing your medications: An automated medication reminder application for mobile phones and hypertension medication adherence in a high-risk urban population. Journal of Diabetes Science and Technology, 7(3), 630-639.

59. Grimm, R. H., Grandits, G. A., Cutler, J. A., Stewart, A. L., McDonald, R. H., Svendsen, K., Prineas, R. J., \& Liebson, P. R. (1997). Relationships of quality-of-life measures to long-term lifestyle and drug treatment in the treatment of mild hypertension study. Archives of Internal Medicine, 157(6), 638-648.

60. Katsi, V., Kallistratos, M. S., Kontoangelos, K., Sakkas, P., Souliotis, K., Tsioufis, C., Nihoyannopoulos, P., Papadimitriou, G. N., \& Tousoulis, D. (2017). Arterial hypertension and healthrelated quality of life. Frontiers in Psychiatry, 8, 270.

61. Park, N. H., Song, M. S., Shin, S. Y., Jeong, J. H., \& Lee, H. Y. (2018). The effects of medication adherence and health literacy 
on health-related quality of life in older people with hypertension. International Journal of Older People Nursing, 13(3), e12196.

62. Papadopoulos, A. A., Kontodimopoulos, N., Frydas, A., Ikonomakis, E., \& Niakas, D. (2007). Predictors of health-related quality of life in type II diabetic patients in Greece. BMC Public Health, 7(1), 186
Publisher's Note Springer Nature remains neutral with regard to jurisdictional claims in published maps and institutional affiliations. 